Supplement of Saf. Nucl. Waste Disposal, 1, 53-55, 2021

https://doi.org/10.5194/sand-1-53-2021-supplement

(c) Author(s) 2021. CC BY 4.0 License.

Supplement of

\title{
A systematic approach for surface exploration of sites - a database to research and evaluate suitable methods
}

Raphael Dlugosch et al.

Correspondence to: Raphael Dlugosch (raphael.dlugosch@bgr.de)

The copyright of individual parts of the supplement might differ from the article licence. 


\section{A systematic approach for surface exploration of sites - a database to research and evaluate suitable methods}

Dlugosch, R. ${ }^{1}$, Beilecke, T., Kneuker, T., Pollok, L., Richter, L., Schubarth-Engelschall, N., Semroch, R. Federal Institute for Geosciences and Natural Resources (BGR), Hannover, Germany
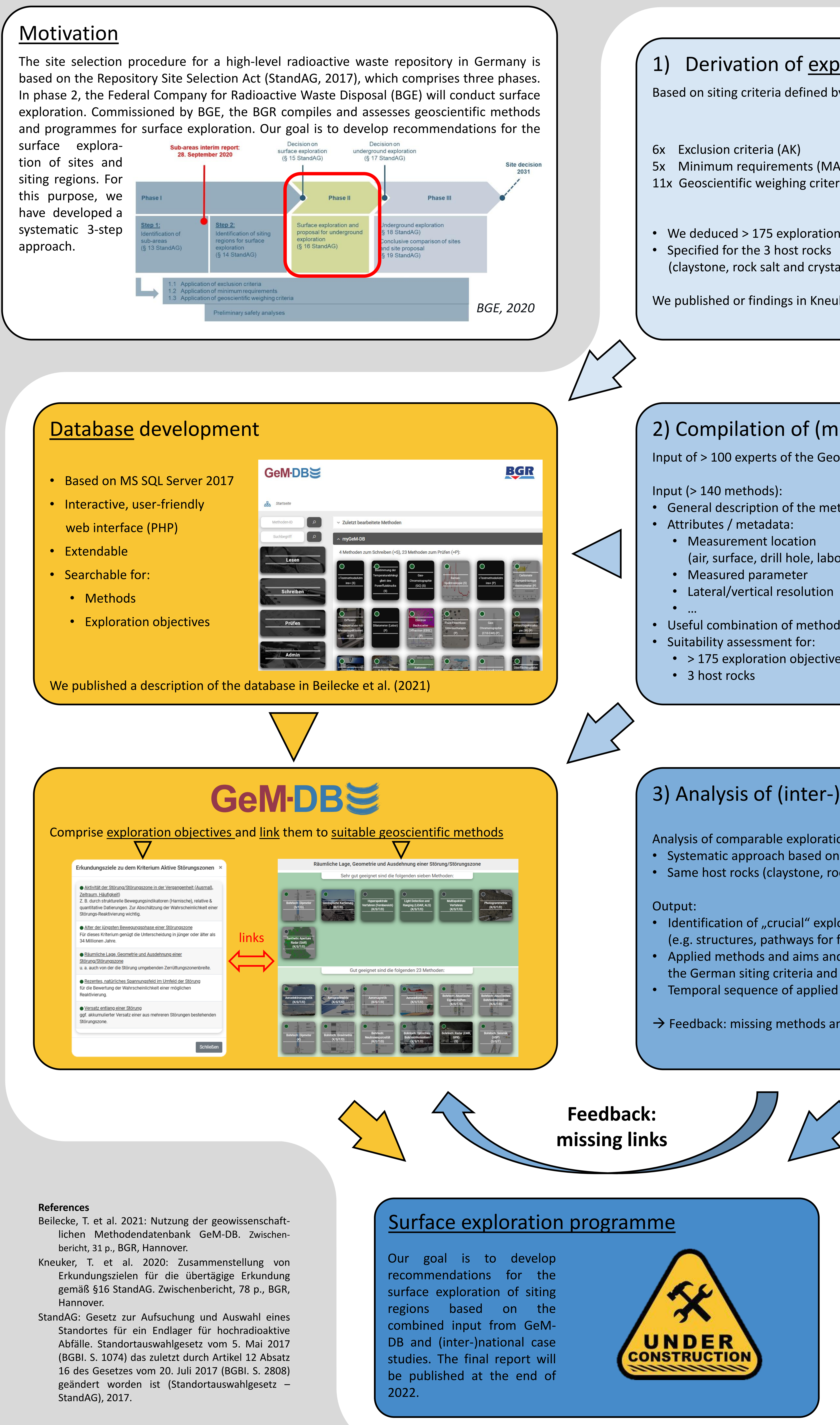

1) Derivation of exploration objectives

Based on siting criteria defined by StandAG

$\begin{array}{ll}\text { 6x } & \text { Exclusion criteria (AK) } \\ 5 x & \text { Minimum requirements (MA) }\end{array}$

11x Geoscientific weighing criteria (AwK)

- We deduced $>175$ exploration objectives

- Specified for the 3 host rocks

(claystone, rock salt and crystalline rock)

We published or findings in Kneuker et al. (2020)
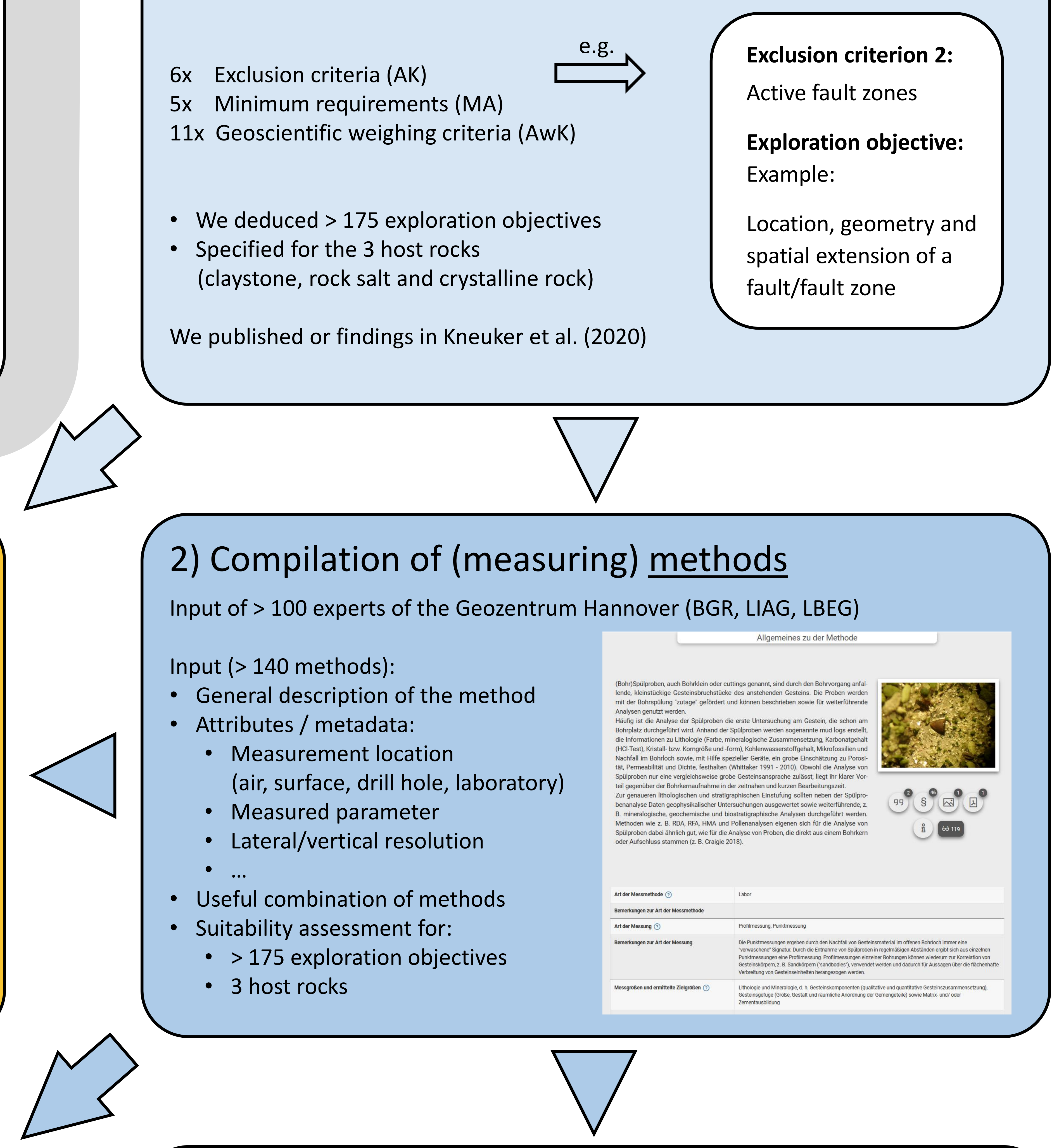

3) Analysis of (inter-)national exploration programmes

Analysis of comparable exploration programmes:

- Systematic approach based on (geo-)scientific criteria

- Same host rocks (claystone, rock salt or crystalline rock)

Output:

- Identification of crucial" exploration objectives

(e.g. structures, pathways for fluids, lithology)

Applied methods and aims and their "translation" into

the German siting criteria and requirements (StandAG)

- Temporal sequence of applied methods

$\rightarrow$ Feedback: missing methods and links

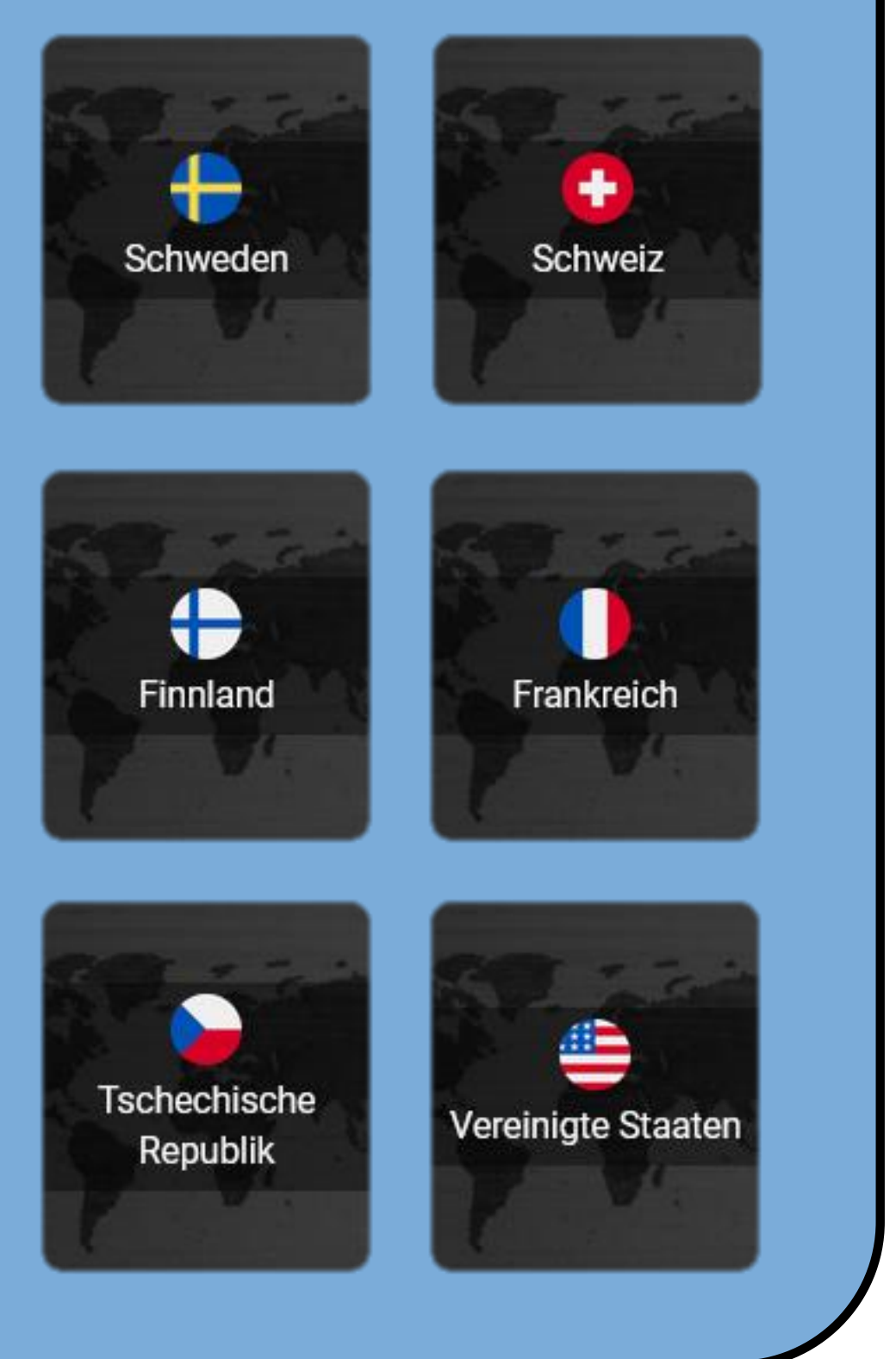

\section{Conclusions}

- We defined $>175$ exploration objectives from StandAG

- We developed the database GeM-DB to link, archive, and research methods and exploration objectives

- (Inter-)national exploration programmes help us to:

- Identify missing methods

- Identify missing links to exploration objectives

- Assess temporal sequence of methods

- We use GeM-DB as a "tool“ to

- Analyse (inter-)national case studies

- Identify suitable methods for exploration objectives See also our talk Richter et al., Fri. 10:40-11:00, Session 2B 